\title{
ORIGINALARTICLE
}

\section{Prune belly syndrome: a South African perspective}

\author{
Shannon D Leahy, Udai Kala, Karen L Petersen \\ Department of Paediatrics, University of the Witwatersrand and Chris Hani Baragwanath Academic Hospital, Johannesburg, South Africa.
}

\section{ABSTRACT}

Background: Prune belly syndrome (PBS) is a rare congenital disorder with a triad of signs: absent abdominal wall musculature, urinary tract malformations, and cryptorchidism. The aims of this study were to describe the epidemiology, renal function, management and outcome of patients with PBS at the Chris Hani Baragwanath Academic Hospital, Johannesburg, South Africa.

Methods: A retrospective record review was conducted of patients with PBS referred to the paediatric nephrology unit from 1984 to 2014.

Results: A total of 44 patient records were analysed. Most of the patients presented as neonates ( $n=35,80 \%)$. The accompanying congenital malformations included urological problems (21, 48\%), orthopaedic abnormalities (5, I1\%), congenital heart disease $(3,7 \%)$ and gastrointestinal abnormalities (2, 4\%). The medical management included the use of prophylactic antibiotics and intermittent bladder catheterisation. Surgical management included abdominoplasty with orchidopexy and circumcision. At the last clinic visit, severe reductions in renal function were noted in II (58\%) of the patients under the age of 2 years, whereas normal renal function was present in 14 (56\%) of the patients over 2 years of age. The default rate was 57\%; 6 (14\%) patients were transferred to an adult clinic and 2 (4\%) patients died.

Conclusions: The patient profiles and the management recorded are comparable with other reported series. There are differences in the frequencies of congenital malformations and the rates of surgical intervention. The renal outcome for children older than two years was favourable compared to younger children. Progression to end-stage renal disease was observed infrequently, but this may be underestimated in view of the high default rate.

Keywords: Prune belly syndrome, South Africa.

\section{INTRODUCTION}

Prune belly syndrome (PBS) is a rare congenital disorder characterised by a triad of signs with a wide variability of clinical manifestations and severity $[1,2]$. The complete syndrome is seen only in males and manifests with deficient or absent abdominal wall musculature, urinary tract malformations (megacystis, megaureters, hydronephrosis and renal dysplasia) and bilateral cryptorchidism [1-6]. Male patients make up between 90-95\% of the cases of PBS $[1,6]$. Female patients have the characteristic abdominal wall appearance as well as malformations of the urinary tract [3].
The incidence of PBS in the United States is 3.8/100 000 live births [2,3]. Most cases of PBS occur sporadically, although a few familial cases of the condition suggest an $X$-linked mode of inheritance [7-10]. No data are available in South Africa. There are two main theories regarding the aetiology of the condition [4,7]. The first theory is explained by an early functional urethral obstruction by a valve-like mechanism which causes a sequence of events leading to the renal manifestations $[4,7,1 \mathrm{l}]$. The second theory suggests a mesenchymal developmental arrest during early embryogenesis $[3,4,12]$. 
The urinary system in PBS is dilated, but with low pressure and non-obstructive in nature $[1,4,1 \mathrm{I}]$. Owing to varying degrees of parenchymal dysplasia and recurrent damage from infection and subsequent scarring of the kidney, endstage renal disease (ESRD) may occur [4]. Vesicoureteric reflux (VUR) may be present in up to $75 \%$ of patients with PBS $[|, 3| 3$,$] . The abdomen has a wrinkled, drooping$ appearance due to partial or total dysplasia of the muscular wall $[I]$. The failure of descent of the testicles is probably due to a mechanical barrier attributable to the dilated urinary system [7].

A dilated urinary system and oligohydramnios can be seen antenatally using ultrasound, so that the diagnosis is then suspected [3]. Less than $50 \%$ of pregnant women in the urban government hospitals in South Africa have access to an ultrasound before 24 weeks of gestation and thus the diagnosis is usually made postnatally [14].

Congenital malformations accompanying PBS are a frequent occurrence, which can affect the outcome of patients [I]. Respiratory system complications include poor respiratory mechanics due to the weak diaphragmatic musculature as well as pulmonary hypoplasia $[1,4,15]$. Gastrointestinal problems are seen in up to $30 \%$ of patients with PBS; these include atresias, malrotations and omphalocoeles $[1,2,4]$. Clubfeet and congenital dislocation of the hip are present in 30-40\% of patients, depending on the degree of oligohydramnios $[1,4]$. Congenital heart disease $(\mathrm{CHD})$ has also been associated with PBS $[1,4,5]$. In addition, cystic kidney disease, posterior urethral valves (PUV) and urachal abnormalities have been described [2,3,9].

Patients can be classified in terms of mild, moderate and severe forms of the syndrome based on their renal function [13]. This classification system helps to prognosticate the general outcome of patients [13]. Up to 20\% fall into the severe category presenting with severe renal dysplasia, oliguria and pulmonary hypoplasia $[1,13]$. There is a high incidence of stillbirth and early neonatal mortality in this category $[1,16]$. Up to $30-40 \%$ of the cases are in the moderate category with marked renal dysplasia and progressive renal failure $[1,13]$. The mild group accounts for $40 \%$ of the cases with mild renal dysplasia and varying degrees of urinary collecting system dilatation [I, I3].

The main aim of management is to preserve renal function and prevent infection in the urinary tract [3]. Conservative management includes prophylactic antibiotics, and double voiding with or without intermittent catheterisation $[3,5]$. Initial surgical management includes temporary urinary diversion and major corrective surgery of the dilated urological system to improve urinary drainage $[1,5, \mid 9]$.
Later, abdominal wall reconstruction and orchidopexy is performed [1,5]. More recently, an individually tailored approach that encompasses urinary tract reconstruction, bilateral orchidopexy and abdominoplasty in one operation has been proposed [13].

Circumcision prevents colonisation of the urinary tract and, together with antibiotic prophylaxis, may reduce urinary tract infection (UTI) rates [20]. Peritoneal dialysis has been successful in patients with PBS and ESRD [17]. Renal transplantation has also been shown to be successful in patients with PBS who require renal replacement therapy [19].

There are only a few case reports of PBS from the African continent; Hammond et al. described two cases from South Africa in 1974 [21-23]. The aims of the study reported here were to describe the epidemiology, renal function, management and outcome of patients with PBS seen at the Chris Hani Baragwanath Academic Hospital (CHBAH), South Africa. $\mathrm{CHBAH}$ is a tertiary institution serving the community of Soweto in Johannesburg. It is also a referral centre for patients within Gauteng province and surrounding provinces and countries. The Paediatric Nephrology unit at the $\mathrm{CHBAH}$ attends to paediatric patients with a variety of renal conditions needing specialised care.

\section{METHODS}

We conducted a retrospective review of patients diagnosed with PBS over a period of 31 years. Those with PBS who attended the CHBAH's Paediatric Nephrology clinic from I January 1984 to 31 December 2014 were included. Ethical clearance was granted by the Human Research Ethics Committee (Medical) of the University of the Witwatersrand (clearance no. M|4|| |3).

Patient information was retrieved from the hospital records and captured using the REDCap ${ }^{\text {TM }}$ platform. Data collected included information on demographics, clinical features, anthropometry, renal function, and management received. Congenital malformations were differentiated according to anatomical systems. Outcome was classified in four categories: active, died, transferred to adult clinic, and defaulted. The active category included all the patients that are still attending the nephrology clinic. The last clinic visit was defined as the last clinical record noted.

The renal function at first presentation and at the last clinic visit were recorded, using the Schwartz formula to calculate the estimated glomerular filtration rate (eGFR) [24-26]. Serum creatinine was measured by the National Health Laboratory Service at the $\mathrm{CHBAH}$ using a modified Jaffe method on a Roche Cobas $® 8000$ machine [27]. 
Table I. Severity of the syndrome by categories of GFR.

\begin{tabular}{|cccc|}
\hline Age & Normal eGFR & $\begin{array}{c}\text { Moderately } \\
\text { reduced eGFR }\end{array}$ & $\begin{array}{c}\text { Severely } \\
\text { reduced eGFR }\end{array}$ \\
\hline$<2$ years & 0 to - I SD & $>-1$ to -2 SD & $>-2$ SD \\
$>2$ years & CKD stage I & $\begin{array}{c}\text { CKD stages 2 } \\
\text { and 3 }\end{array}$ & $\begin{array}{c}\text { CKD stages 4 } \\
\text { and 5 }\end{array}$ \\
\hline
\end{tabular}

The eGFR was used to categorise patients in terms of stages I-5 chronic kidney disease (CKD) using the National Kidney Foundation's Kidney Disease Outcomes Quality Initiative Classification for patients over the age of 2 years [24,25]. The eGFR for children under the age of 2 years does not fit this classification and thus was calculated and then stratified using standard deviations with population norms $[26,28]$. They were classified according to moderate $(-1$ to $-2 \mathrm{SD})$ and severe $(>-2 \mathrm{SD})$ reduction in their GFR $[25,26,28]$.

Patients in the two age groups were then categorised as having normal eGFR, a moderate reduction or a severe reduction in eGFR (Table I).

Data were analysed using Microsoft Excel $2010^{\circledR}$ and Statistica version $12^{\circledR}$. Means and standard deviations (SD) were used to represent normally distributed data, whereas medians and interquartile ranges (IQR) represented nonparametric data.

\section{RESULTS}

Table 2 summarises the patient characteristics, management and outcome in respect of the study participants. The diagnosis of PBS was made by the referring clinician based on the clinical characteristics present. No patient was diagnosed antenatally.

The extra-renal congenital malformations associated with PBS in our patients are summarised in Table 3.

Patients were categorised according to renal function at the first and last clinic visits. At the first visit, 19 patients were in the mild category regarding renal impairment, 13 were in the moderate category and 12 were in the severe category (Figure I).

Nineteen patients (43\%) were less than 2 years of age at the last clinic visit. At presentation, the mean age of these patients was $12.2 \pm 14.7$ days and at the last visit $2.7 \pm 2.5$ months. Their eGFR is represented in Figure 2. Fifty-eight percent were in the severely-reduced GFR category at the last clinic visit. However, an improvement in the mean eGFR was noted on comparing the last clinic visit with the
Table 2. Patient demographics, management and outcome.

\begin{tabular}{|c|c|c|c|}
\hline & $\mathrm{N}(\%)$ & $\begin{array}{l}\text { Mean } \\
( \pm S D)\end{array}$ & $\begin{array}{c}\text { Median } \\
(\text { IQR) }\end{array}$ \\
\hline Number of patients & 44 & & \\
\hline \multicolumn{4}{|l|}{ Gender: } \\
\hline Male & $40(9 \mid)$ & & \\
\hline Female & $4(9)$ & & \\
\hline \multicolumn{4}{|l|}{ Race: } \\
\hline Black & $42(96)$ & & \\
\hline White & I (2) & & \\
\hline Mixed & I (2) & & \\
\hline Age at presentation: & & & $\begin{array}{c}5.5 d \\
(2.5-24)\end{array}$ \\
\hline Birth & $8(18)$ & & \\
\hline$<\mid$ month & $27(62)$ & & \\
\hline I-12 months & $3(7)$ & & \\
\hline I-5 years & $5(||)$ & & \\
\hline$>5$ years & I (2) & & \\
\hline Age at last clinic date: & & & $\begin{array}{c}31 \mathrm{~m} \\
(2-131)\end{array}$ \\
\hline Duration of follow-up: & & & $\begin{array}{c}24 \mathrm{~m} \\
(1.7-130)\end{array}$ \\
\hline
\end{tabular}

\section{Anthropometry (Z score):}

Birth wt. for age

BMI at last visit, $>5 \mathrm{yr}$

\section{Medical management:}

Prophylactic antibiotics

Surgical management:

Renal transplant

Urinary diversion

\section{Outcome:}

Death

Transferred

Active 


\begin{tabular}{|c|c|c|c|c|}
\hline System & $\mathrm{n}$ & $\%$ & Type & $N$ \\
\hline Urological & 21 & 48 & $\begin{array}{l}\text { Vesicoureteral reflux } \\
\text { Patent urachus } \\
\text { Suspected posterior urethral } \\
\text { valves }\end{array}$ & $\begin{array}{c}12 \\
5 \\
4\end{array}$ \\
\hline $\begin{array}{l}\text { Orthopaedic/ } \\
\text { Musculoskeletal }\end{array}$ & 5 & 11 & $\begin{array}{l}\text { Bilateral clubbed feet } \\
\text { Congenital hip dysplasia } \\
\text { Spina bifida occulta }\end{array}$ & $\begin{array}{l}3 \\
1 \\
1\end{array}$ \\
\hline Cardiovascular & 3 & 7 & $\begin{array}{l}\text { Patent ductus arteriosus } \\
\text { Supravalvular pulmonary } \\
\text { stenosis }\end{array}$ & $\begin{array}{l}2 \\
1\end{array}$ \\
\hline Gastrointestinal & 2 & 4 & Omphalocoele & 2 \\
\hline
\end{tabular}

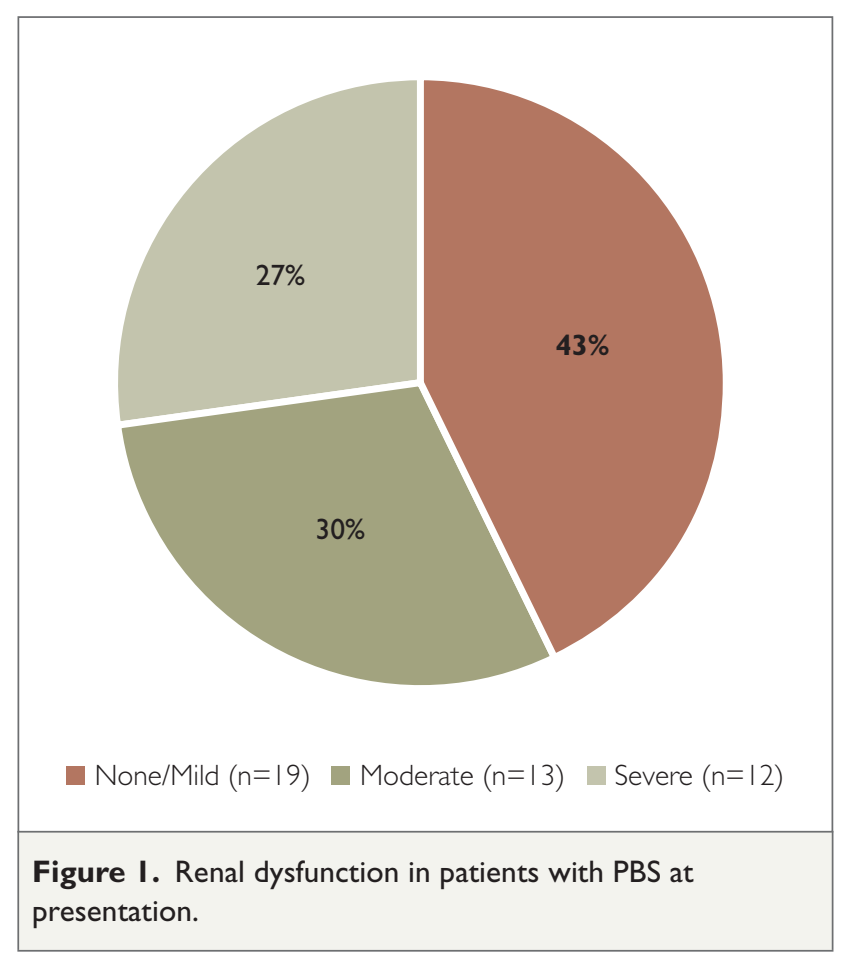

Twenty-five patients (57\%) were over 2 years of age at the last clinic visit. Fifty-six percent of these patients had normal renal function and only one had advanced to stage 5 CKD at the last clinic visit (Figure 4).

\section{DISCUSSION}

Most patients in this study were Black, male children with the complete triad of signs. This is similar to what has been described in the literature. The diagnosis of PBS was made clinically, and mostly during the neonatal period, rather than antenatally.

Prophylactic antibiotic therapy to prevent UTI was used in $84 \%$ of the patients, which is comparable to the conservative management reported in other studies [2,29].

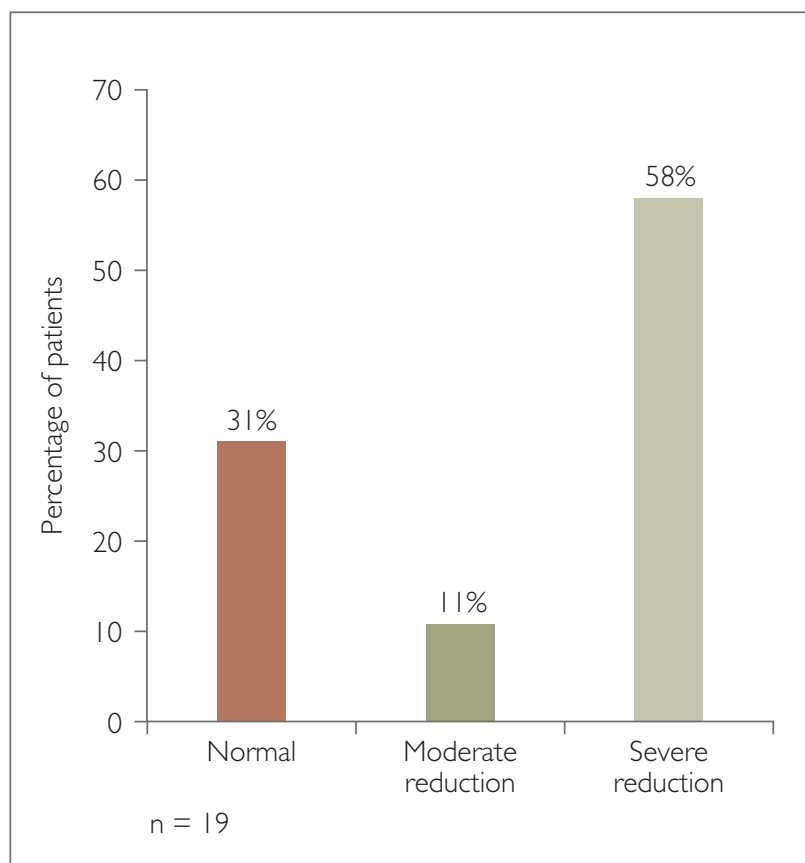

Figure 2. eGFR of patients less than 2 years of age at the last clinic visit.

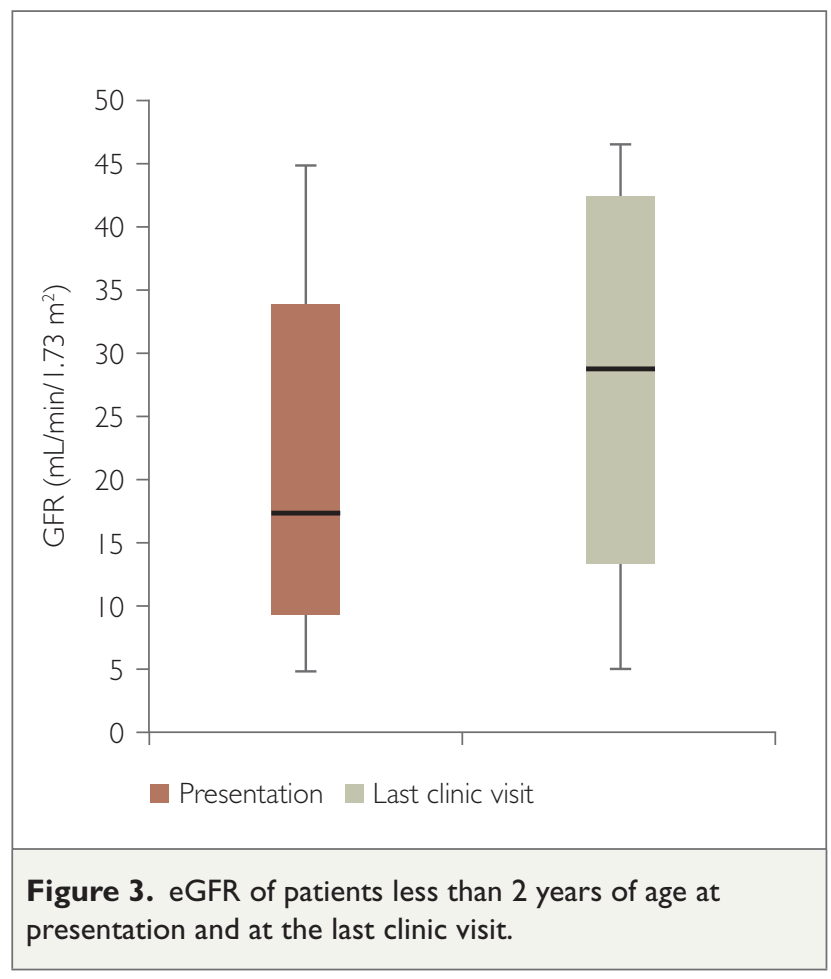

Newer recommendations are discouraging the use of prophylactic antibiotics in patients with recurrent UTIs with or without structural urological conditions [18]. Reasons for this include the risk of antibiotic resistance and the lack of benefit regarding the reduction of renal scarring $[18,30]$. In the last ten years, intermittent catheterisation has become widely used in the management of PBS. Intermittent catheterisation was initiated in $30 \%$ of the patients in 


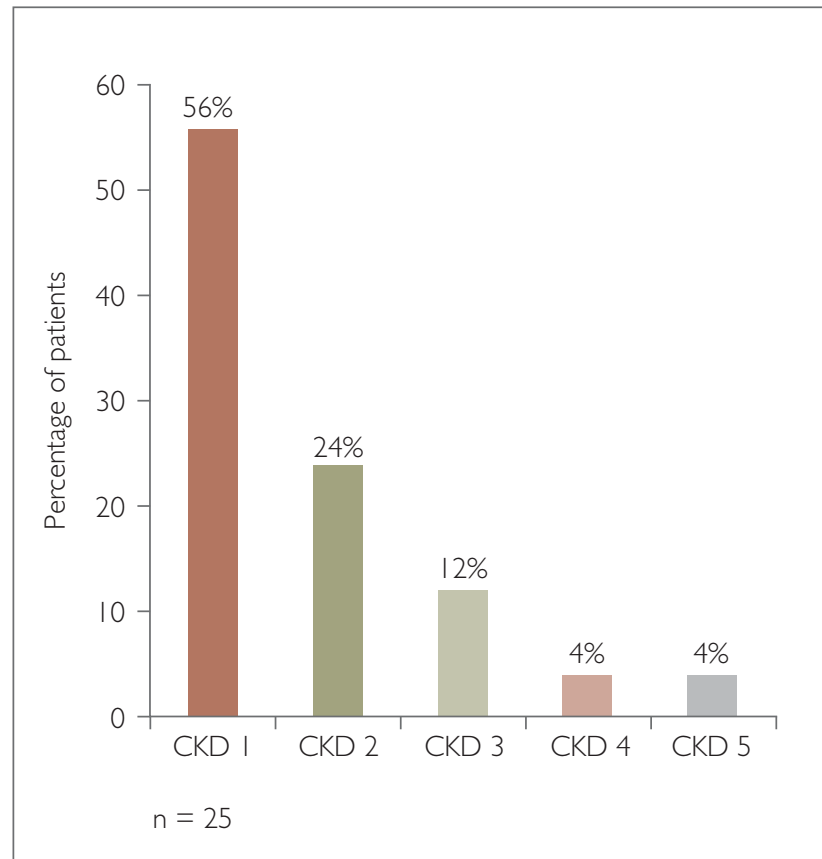

Figure 4. eGFR of patients less than 2 years of age at the last clinic visit.

this study. The age of starting intermittent catheterisation was much later in comparison with the use of prophylactic antibiotics. Intermittent catheterisation can be uncomfortable and painful, contributing to the patient's reluctance to comply with it. It is more difficult in younger patients and in uncircumcised boys.

Fifty percent of the patients had surgical interventions; this rate is less than in other reports $[1,2]$. Elective operations were planned after the age of 2 years in conjunction with our paediatric surgeons. This age requirement and the high default rate could contribute to the lower surgery rates documented.

Fifty-seven percent of the patients defaulted on scheduled clinic appointments. The reasons may include challenges with large travelling distances, financial constraints and lack of social services that are often encountered in developing countries [31,32]. Eleven percent of patients were transferred to the adult renal clinic for further care. It was not established whether any of these patients went on to have renal replacement therapy. Two patients died during the neonatal period.

Gastrointestinal abnormalities were documented less frequently than in published reports. Two patients had omphalocoeles, which were surgically corrected. The orthopaedic conditions we observed are well described in patients with PBS, with clubfeet being the most common
Urological conditions occurred frequently. VUR was seen in $27 \%$ of the patients, which is lower than in other reports $[2,3,13]$. Patent urachus was noted in $11 \%$, and $9 \%$ of the patients had radiological evidence of PUV. Urachal abnormalities as well as PUV are not well documented in the literature $[2,9]$.

Whereas most of our patients were in the severely-reduced GFR category at the last clinic visit, there was an overall improvement in GFR, which might be related to the normal maturation of renal function or the effective treatment of complications, such as UTI, that may have been present at the first visit. Only one patient developed ESRD, a significantly lower rate than the approximately $30 \%$ reported in the literature [17]. No patient received renal replacement therapy; the single patient with CKD stage 5 was lost to follow-up at 8 years of age.

Limitations of this study include its retrospective nature and the small study population. Neonates not presenting to our clinic due to early death may contribute to referral bias and underestimation of the numbers in the severe group of patients.

\section{CONCLUSIONS}

Our patients with PBS who were older than 2 years had good renal outcomes. Poorer outcomes in the younger patients is most likely due to the severity of the syndrome and associated complications such as urinary sepsis. Suspected PUV and urachal abnormalities were noted relatively frequently.

Early referral to a specialised unit is essential to ensure optimal outcomes in patients with PBS. Prompt treatment of UTIs and prevention of recurring infection is important. Routine voiding cystourethrograms, with cystoscopy if required, is recommended due to the frequent occurrence of urachal abnormalities and PUV.

\section{REFERENCES}

I. Zugor V, Schott GE, Labanaris AP. The prune belly syndrome: urological aspects and long-term outcomes of a rare disease. Pediatr Rep. 2012; 4(2):e20.

2. Routh JC, Huang L, Retik AB, Nelson CP. Contemporary epidemiology and characterization of newborn males with prune belly syndrome. Urology. 2010; 76(I):44-48.

3. Hassett $\mathrm{S}$, Smith GH, Holland AJ. Prune belly syndrome. Pediatr Surg Int. 2012; 28(3):219-228.

4. Murray PJ, Thomas K, Mulgrew CJ, Ellard S, Edghill EL, Bingham C. Whole gene deletion of the hepatocyte nuclear factor- I $B$ gene in a patient with the prune-belly syndrome. Nephrol Dial Transplant. 2008; 23(7):2412-2415. 
5. Seidel N, Arlen A, Smith E, Kirsch A. Clinical manifestations and management of prune-belly syndrome in a large contemporary pediatric population. Pediatr Urol. 2015; 85:2II-2I5.

6. Mesrobian H, Balcom A, Durkee C. Urologic problems of the neonate. Pediatr Clin N Am. 2004; 51:1051-1062.

7. Moerman P, Fryns JP, Goddeeris P, Lauweryns JM. Pathogenesis of the prune-belly syndrome: a functional urethral obstruction caused by prostatic hypoplasia. Pediatrics. 1984; 73(4):470-475.

8. Ramasamy R, Haviland M, Woodard JR, Barone JG. Patterns of inheritance in familial prune belly syndrome. Urology. 2005; 65(6): 1227.

9. Giuliani S, Vendryes C, Malhotra A, Shaul DB, Anselmo DM. Prune belly syndrome associated with cloacal anomaly, patent urachal remnant, and omphalocele in a female infant. J Pediatr Surg. 2010; 45(I I):e39-42.

10. Weber S, Thiele H, Mir S, Toliat MR, Sozeri B, Reutter H, et al. Muscarinic acetylcholine receptor M3 mutation causes urinary bladder disease and a prune-belly-like syndrome. Am J Hum Genet. 2011; 89(5):668-674.

I I. Zelikovic I, Dabbagh S, Friedman AL, Uehling DT, Chesney RW. Good outcome in prune-belly syndrome despite associated severe anomalies. Pediatr Nephrol. 1988; 2(4):5 I2-5 | 4.

12. Panitch H. Pulmonary complications of abdominal wall defects. Paediatr Respir Rev. 2015; 16:11-17.

13. Denes FT, Arap MA, Giron AM, Silva FA, Arap S. Comprehensive surgical treatment of prune belly syndrome: 17 years' experience with 32 patients. Urology. 2004; 64(4):789-793.

14. Stewart C. The magic of ultrasound. S Afr J Obstet Gynaecol. 201 I; 17(3):54-55.

15. Crompton CH, MacLusky IB, Geary DF. Respiratory function in the prune-belly syndrome. Arch Dis Child. 1993; 68(4):505-506.

16. Zugor V, Gunter S, Labanaris A. The prune belly syndrome: urological aspects of a rare disease. Pediatr Rep. 2012; 4(20): $78|-8| \mid$.

17. Crompton $\mathrm{CH}$, Balfe JW, Khoury A. Peritoneal dialysis in the prune belly syndrome. Perit Dial Int. 1994; I4(1): 17-21.

18. Robinson J, Finlay J, Lang M, Bortolussi R. Prophylactic antibiotics for children with recurrent urinary tract infections. Paediatr Child Health. 2015; 20(I): 45-47.

19. Fontaine E, Salomon L, Gagnadoux MF, Niaudet P, Broyer M, Beurton D. Long-term results of renal transplantation in children with the prune-belly syndrome. J Urol. 1997; I58(3 Pt I):892-894.

20. Gucuk A, Burgu B, Gokce I, Mermerkaya M, Soygur T. Do antibiotic prophylaxis and/or circumcision change periurethral uropathogen colonization and urinary tract infection rates in boys with VUR? J Pediatr Urol. 2013; 9: I |31-1136.

21. Kheir A, Ali E, Medani S, Maaty H. Prune belly syndrome: A report of 15 cases from Sudan. Sudan J Paediatr. 2017; 17(I):42-48.

22. Chapp-Jumbo A, Onyire B, Ulonnam N, Ikpeme E. Growing up with prune belly syndrome in a resource poor setting. Afr J Paed Nephrol. 20।4; I (2).

23. Hammond J, Van Den Eende E, Boardman R, Mather B. Prune belly syndrome. S Afr Med J. 1974; 48:839-840.

24. Gao A, Cachat F, Faouzi M, Bardy D, Mosig D, Meyrat B, et al. Comparison of the glomerular filtration rate in children by the new revised Schwartz formula and a new generalized formula. Kidney Int. 2012; 83:524-530.

25. Hogg R, Furth S, Lemley K, Portman R, George J, Schwartz J et al. National Kidney Foundation's Kidney Disease Outcomes Quality Initiative clinical practice guidelines for chronic kidney disease in children and adolescents: evaluation, classification and stratification. Pediatrics. 2003; | | |:|4|6-|42|.
26. Schwartz G, Brion L, Spitzer A. The use of plasma creatinine concentration for estimating glomerular filtration rate in infants, children, and adolescents. Pediatr Clin N Am. 1987; 34(3):57I-590.

27. Package insert for Roche cobas c CREJ2 creatinine assay.

28. KDOQI Clinical Practice Guidelines for Chronic Kidney Disease: Evaluation, Classification, and Stratification. Am J Kidney Dis. 2002; 39:SI-S266.

29. Woodhouse CR, Ransley PG, Innes-Williams D. Prune belly syndrome-report of 47 cases. Arch Dis Child. 1982; 57(I I): 856-859.

30. Montini G, Hewitt I. Urinary tract infections: to prophylaxis or not to prophylaxis? Pediatr Nephrol. 2009; 24:1605-1609.

31. Chatterjee SK, Banerjee S, Basak D, Basu AK, Chakravarti AK, Chatterjee US, et al. Posterior urethral valves: the scenario in a developing center. Pediatr Surg Int. 200 I; 17(1):2-7.

32. Orumuah AJ, Oduagbon OE. Presentation, management, and outcome of posterior urethral valves in a Nigerian tertiary hospital. Afr J Paediatr Surg. 2015; 12(1):18-22. 